\title{
Progressive multi-focal leukoencephalopathy as a rare lethal complication in untreated sarcoidosis
}

\author{
Sabine K Hohlfeld, ${ }^{1}$ Huldrych F Günthard, ${ }^{2}$ Jonas Zeitz, ${ }^{1}$ Pascal Locher, ${ }^{1}$ Esther Bachli ${ }^{3}$ \\ ${ }^{1}$ Department of Internal Medicine, University Hospital Zurich, Zurich, Switzerland; \\ 2Division of Infectious Diseases and Hospital Epidemiology, University Hospital Zurich, Zurich, Switzerland; \\ ${ }^{3}$ Department of Internal Medicine, Uster Hospital, Uster, Switzerland \\ Correspondence to PD Dr Esther Bachli, esther.Baechli@spitaluster.ch
}

\section{Summary}

Progressive multi-focal leukoencephalopathy (PML) is a demyelinating disease of the central nervous system caused by reactivation of John Cunningham virus. It is an opportunistic infection affecting patients who are severely immunocompromised due to an underlying disease or secondary to immunosuppressive therapy. To date, no effective antiviral therapy has been established, though several substances are being investigated. The authors present the case of a 39-year-old previously healthy patient who was diagnosed with PML and sarcoidosis stage III without having received prior immunosuppressive treatment. The patient did not respond to treatment with mirtazapine, which has been used empirically, and deceased shortly after diagnosis.

\section{BACKGROUND}

Generally, progressive multi-focal leukoencephalopathy (PML) occurs as an opportunistic infection in severely immunosuppressed patients. It is seen mostly in untreated HIV-infected patients (AIDS defining illness) and also in transplant patients and recently it has also been described in patients with multiple sclerosis treated with natalizumab. In our case, however, we did not have a classical state of immunodeficiency. Thus, it represents a very rare case and should remind physicians to think of PML also in atypical diseases.

\section{CASE PRESENTATION}

A 39-year-old Portuguese patient presented with left-sided weakness and hypoesthesia, which had developed over a period of days. Additionally, he had lost $13 \%$ of his bodyweight during the past 2 months and suffered from nonproductive cough for several weeks. To date, he had been healthy and had not received any medication. The family history was non-contributory. Neurological examination revealed mild paresis and hypoesthesia of the left limb, left-sided hyperreflexia, gait ataxia, left haemianopsia and hemineglect.

\section{INVESTIGATIONS}

Chest X-ray and a CT scan showed a pronounced mediastinal lymphadenopathy and reticulo-nodular lung tissue densities consistent with advanced sarcoidosis (stage III) as well as a marked splenomegaly $(22 \mathrm{~cm})$. The bronchoalveolar lavage displayed an elevated CD4+/CD8+ ratio (factor 5.6). Lung and bone marrow biopsies showed non-caseating granulomas, suggestive of sarcoidosis. Other granulomatous diseases were ruled out by serological testing.

Cranial MRI revealed large hyper dense areas on T2-weighted images, located in the subcortical white mat- ter of the right temporal and occipital lobe as well as in the thalamus and adjacent structures (figure 1).

Normal cell counts, protein and glucose levels were measured in the cerebrospinal fluid (CSF) and no oligoclonal bands were detected. PCR testing for cytomegalovirus, Epstein-Barr virus, herpes simplex virus and varicella zoster virus replication was negative. Yet John Cunningham virus (JCV)-specific DNA was detected repeatedly in the CSF, without JCV replication in blood or urine samples.

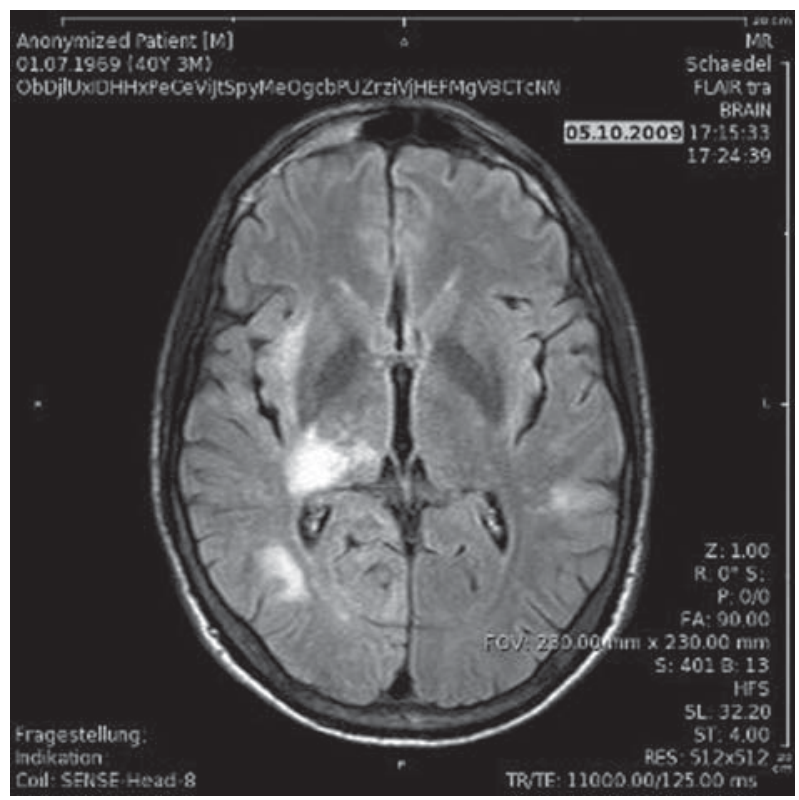

Figure $1 \mathrm{MRI}$ fluid attenuated inversion recovery scans showed an area of hyperintense signal in the subcortical white matter of the right temporal and occipital lobe as well as in the thalamus and adjacent structures. 
A stereotactic brain biopsy was performed, showing neuropathological changes characteristic of PML, namely focal white matter destruction with JCV-infected oligodendrocytes (as confirmed by immunohistochemistry).

Laboratory tests revealed an elevated level of ACE, polyclonal gammopathy, a reduced lymphocyte count (600 cells/ $\mu 1)$ and severely suppressed CD4+ lymphocyte fraction (171 cells/ $\mu \mathrm{l})$, whereas the $\mathrm{CD} 4+/ \mathrm{CD} 8+$ ratio was normal. No autoantibodies could be detected and HIV infection was ruled out by repetitive screening, HIV RNA and p24 ag tests as well as a particle associated elevated reverse transcriptase test to detect potential retroviral activity not detected by standard HIV tests.

\section{DIFFERENTIAL DIAGNOSIS}

PML, neurosarcoidosis.

\section{TREATMENT}

A treatment with mirtazapine was initiated $(15 \mathrm{mg} / \mathrm{d})$. Clinically, and confirmed by follow-up MRI of the brain 4 weeks after the initial imaging, no progression of the disease was noted. Concerning sarcoidosis, the patient was asymptomatic apart from a slight restrictive ventilatory impairment. Corticosteroids were not administered.

\section{OUTCOME AND FOLLOW-UP}

Six weeks after diagnosis, the left-sided hemiparesis had worsened and the patient showed severe altered mental status and had suffered a generalised seizure.

Progression of PML was confirmed in a CT scan. Given the profound clinical deterioration no further treatment was undertaken and the patient died 1 month later, that is, 2 months after diagnosis. Permission for autopsy was not granted.

\section{DISCUSSION}

The clinical and virological findings and pathologic changes on neuroimaging in this patient were consistent with the diagnosis of PML, a brain biopsy ruled out other potentially treatable diseases. Simultaneously, our patient was found to have sarcoidosis stage III. PML in association with sarcoidosis has mostly been described in patients receiving immunosuppressive therapy, but cases of PML as first manifestation in patients with sarcoidosis have rarely been reported. ${ }^{1}{ }^{2}$

There is no specific treatment for JCV infection. In HIVpositive patients with PML, highly active antiretroviral therapy is the best therapeutic option. In patients receiving immunosuppressive medication, a discontinuation or dose reduction is recommended. ${ }^{3}$

Cytarabine has been shown to decrease JCV replication invitro and appeared to stabilise the clinical status of HIV negative patients with PML. ${ }^{3}$ Cidofovir alone or in combination with mirtazapine has been effective in vivo and in cases of patients suffering from PML and sarcoidosis. ${ }^{2}$ Nevertheless, several clinical studies have reported no benefit from treatment with cidofovir. Mefloquine is currently being evaluated in a multi-centre trial. ${ }^{3}$

Since the 5-hydroxytryptamine-2a serotonin receptor has been identified as being a cellular receptor for JCV, ${ }^{4}$ mirtazapine has been used empirically showing improvement in some cases.

In summary, in HIV negative patients with PML as well as in patients who are not receiving immunosuppressive therapy, no established treatment exists. The mechanisms leading to symptomatic PML in patients without a documented immune defect remain unknown. Considering the sarcoidosis as underlying cause we even discussed a treatment with immunosuppressive therapy to eventually improve the patient's immune response. Because of possibly aggravating JC-infection by this measurement we finally opted for a treatment with mirtazapine alone. Unfortunately, the patient experienced rapid deterioration after initiation of therapy and died 2 months later.

We describe a case of disseminated sarcoidosis without prior immunosuppressive therapy and histologically proven symptomatic PML that did not respond to mirtazapine therapy. The pathophysiologic mechanisms leading to PML in this case remain to be established.

\section{Learning points}

Whereas PML is well known in patients with AIDS and can also rarely occur in patients with immunosuppressive therapy such as for example, natalizumab in patients with multiple sclerosis, in HIVnegative patients it is still a rare but serious disease.

- Sarcoidosis represents an atypical cause of PML because it is not necessarily associated with a classical immunosuppressive state or therapy, as demonstrated in the presented case.

- While treating HIV with antiretroviral therapy and removing immunosuppressive therapy represent therapeutic options in other cases, PML in sarcoidosis is even more difficult to manage since there is no specific treatment of $\mathrm{JC}$-virus and immunosuppression cannot be improved in this case of sarcoidosis.

- PML is a differential diagnosis which has to be considered also in supposedly immunocompetent patients for example, with sarcoidosis and neurological abnormalities.

Acknowledgements The authors thank PD Dr Urs Schwarz, consultant in Neurology, University Hospital Zurich, Switzerland and Professor Dr Hans Hirsch, University Hospital Basel, Switzerland for helpful discussions.

Competing interests None.

Patient consent Obtained.

\section{REFERENCES}

1. Rosenbloom MA, Uphoff DF. The association of progressive multifocal leukoencephalopathy and sarcoidosis. Chest 1983;83:572-5.

2. De Raedt S, Lacor P, Michotte A, et al. Progressive multifoca leukoencephalopathy as first manifestation of sarcoidosis. Clin Neurol Neurosurg 2008;110:186-9.

3. Tan CS, Koralnik IJ. Progressive multifocal leukoencephalopathy and other disorders caused by JC virus: clinical features and pathogenesis. Lancet Neurol 2010;9:425-37.

4. Elphick GF, Querbes W, Jordan JA, et al. The human polyomavirus, JCV, uses serotonin receptors to infect cells. Science 2004;306:1380-3. 


\section{BMJ Case Reports}

This pdf has been created automatically from the final edited text and images.

Copyright 2012 BMJ Publishing Group. All rights reserved. For permission to reuse any of this content visit http://group.bmj.com/group/rights-licensing/permissions.

BMJ Case Report Fellows may re-use this article for personal use and teaching without any further permission.

Please cite this article as follows (you will need to access the article online to obtain the date of publication).

Hohlfeld SK, Günthard HF, Zeitz J, Locher P, Bachli E. Progressive multi-focal leukoencephalopathy as a rare lethal complication in untreated sarcoidosis. BMJ Case Reports 2012;10.1136/bcr.03.2011.4036, Published XXX

Become a Fellow of BMJ Case Reports today and you can:

- Submit as many cases as you like

- Enjoy fast sympathetic peer review and rapid publication of accepted articles

- Access all the published articles

Re-use any of the published material for personal use and teaching without further permission

For information on Institutional Fellowships contact consortiasales@bmjgroup.com

Visit casereports.bmj.com for more articles like this and to become a Fellow

Keep up to date with all published cases by signing up for an alert (all we need is your email address) http://casereports.bmj.com/cgi/alerts/etoc 